\title{
EXENCIÓN DE TRADUCCIONES PARA EFECTOS DE INMIGRACIÓN EN EL MERCOSUR
}

\author{
Mario J. A. Oyarzábal*
}

\begin{abstract}
RESUMEN
Este trabajo analiza el Acuerdo sobre exención de traducción para documentos administrativos para efectos de inmigración entre los Estados Partes del MERCOSUR, Bolivia y Chile, y argumenta que el mismo presenta ciertas deficiencias para las que el autor sugiere soluciones interpretativas.
\end{abstract}

MERCOSUR - INMIGRACIÓN - DERECHO INTERNACIONAL PÚBLICO

Translation exemption in immigration within MERCOSUR

Abstract

This paper analyzes the agreement to exempt administrative documentation from translation for purposes of migration between the MERCOSUR member states, Bolivia and Chile. It argues that this agreement suffers from some weaknesses for which the author suggests interpretative answers.

$$
\text { MERCOSUR - MIGRATION - INTERNATIONAL LAW }
$$

* Abogado, Máster en Derecho, Profesor de Derecho Internacional Privado de la Universidad Nacional de La Plata, Argentina. Correo electrónico: moyarzabal@ post.harvard.edu

Artículo recibido el 14 de marzo de 2006 y aceptado para su publicación por el Comité Editorial el 30 de mayo de 2006. 


\section{Vigencia y Contenidos Substanciales del Acuerdo}

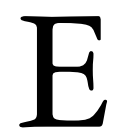

129 de diciembre pasado entró en vigor entre Argentina, Brasil y Chile el Acuerdo sobre exención de traducción para documentos administrativos para efectos de inmigración entre los Estados Partes del MERCOSUR, la República de Bolivia y la República de Chile, suscripto en Florianópolis el 15 de diciembre de 2000, MERCOSUR/CMC/DEC No $45 / 00{ }^{1}$

Conforme a lo previsto en este Acuerdo, los nacionales de cualquiera de los Estados Partes quedan dispensados de la exigencia de traducción de los documentos presentados a efectos de trámites migratorios referentes a solicitud de visa, renovación de plazo de estadía y concesión de permanencia en el territorio de otro Estado Parte (art. 1). La exención de traducción alcanza al pasaporte, cédula de identidad, testimonios de partidas o certificados de nacimiento y de matrimonio, y certificados de ausencia de antecedentes penales de los beneficiarios del Acuerdo (art. 2); salvo que existan dudas fundadas sobre el contenido del documento, en cuyo caso el país de ingreso podrá, excepcionalmente, exigir su traducción (art. 4). El fin del Acuerdo es promover el libre tránsito y la permanencia de los ciudadanos de los países del MERCOSUR, mediante la facilitación del trámite migratorio, en el marco de la integración que une a los Estados Partes; y constituye un importante complemento del Acuerdo sobre residencia para nacionales de los Estados Partes del MERCOSUR, la República de Bolivia y la República de Chile firmado en Brasilia el 6 de diciembre de 2002, MERCOSUR/CMC/DEC No 28/02. ${ }^{2}$

\section{IDIOMAS INCLUIDOS Y EXCLUIDOS}

El Acuerdo sobre exención de traducciones no satisface totalmente las expectativas. En primer lugar, no deja suficientemente en claro si la exención se aplica solamente a los documentos emanados de los Estados Partes y Asociados del MERCOSUR, redactados en sus idiomas oficiales (español o portugués), o también a los procedentes de terceros países, donde el ciudadano argentino, boliviano, brasileño, chileno, paraguayo o uru-

${ }^{1}$ Aprobado en Argentina por ley 25.900, Boletín Oficial de la República Argentina (BO) 15/7/2004; en Brasil por decreto legislativo $\mathrm{N}^{\circ} 198$ de 2004, Diário Oficial da União (DOU) 10/5/2004; y Chile según comunicación al depositario del Acuerdo de 29/11/2005. El Acuerdo se transcribe como anexo a este comentario.

${ }^{2}$ Aprobado en Argentina por ley 25.902, BO 16/7/2004; en Brasil por decreto legislativo 925 de 2005, DOU 16/9/2005; en Bolivia por ley 2831 de 2004, Gaceta Oficial No 2653 de 27/9/2004; y Chile según comunicación al depositario del Acuerdo de 18/11/2005. Este Acuerdo no ha entrado aún en vigor, para lo que se requiere la ratificación por todos los Estados Partes (art. 14). Ver, en general, SAssone, Susana María, "Las condiciones de la movilidad para los ciudadanos en el MERCOSUR: hacia la reconfiguración de las territorialidades transfronterizas", en Territoires et sociétés du MERCOSUR: jeux et unjeux de l'intégration, L’ordinaire Latino-américain, No 196, Institut Pluridisciplinaire pour les Etudes sur l'Amérique Latine á Toulouse, 2004, págs. 50-62; y MArmora, Lelio, "Políticas migratorias consensuadas en América Latina", en Estudios Migratorios Internacionales, año 17, No 50, Buenos Aires, 2003. 
guayo nació, se casó o vivió y que pueden estar redactados en otros idiomas. Pese a los términos amplios del Acuerdo (el artículo 2 exime de traducción a los documentos de los nacionales de los Estados Partes sin más), creo que la tesis restrictiva se impone, a la luz de los antecedentes del Acuerdo (trabajos preparatorios) de los que surge que en ninguna de las instancias negociadoras se consideró la posibilidad de que los documentos exigidos a los nacionales del MERCOSUR para trámites migratorios puedan provenir de un país no mercosureño. Naturalmente que exigir la traducción de documentos redactados en el idioma de un Estado Parte (v.gr. en portugués, que es el idioma oficial de Brasil), cuando provienen de un Estado no parte (v.gr. Portugal), sería irrazonable, y aún podría contravenir el fin del Acuerdo de aumentar la fluidez de circulación de los nacionales del MERCOSUR. Al mismo tiempo, eximir de traducción a los documentos redactados en cualquiera de los idiomas del mundo presentaría una pesada carga para la autoridad de inmigración, que en muchos casos se vería obligada a obtener de oficio y pagar traducciones para trámites que son esencialmente de interés particular; obligación ésta, por lo demás, que nunca estuvo en las mentes de los Estados Partes asumir.

También el artículo 4 podría interpretarse como habilitando al país de ingreso a exigir la traducción cuando las dudas sobre el contenido del documento presentado se funden en el desconocimiento del idioma, o en el idioma mismo (distinto del español o el portugués), utilizado en su redacción. Pero esa no es la intención de la norma, que fue incorporada en previsión de situaciones excepcionales en que un dato sobre el estado o la conducta de la persona contenido en un documento redactado en el idioma de otro Estado Parte y que es esencial para el trámite migratorio, no puede dilucidarse con total certeza sin asistencia técnica especializada (un traductor). Además, la vía del artículo 4 abriría la cuestión de qué idiomas, si no todos, requieren traducción: los que son más o menos entendibles para personas de habla hispana o portuguesa, como el italiano o el francés? O de uso cada vez más generalizado, como el inglés? O que es conocido por el agente consular en razón de sus funciones, o por el funcionario de inmigración por el motivo que fuere, interviniente en el trámite? Nadie pudo haber previsto ni desear tan errático sistema.

En definitiva, la interpretación histórica, que refleja la voluntad real de las partes, es determinante. ${ }^{3}$ La exención de traducción de documentos establecida en el Acuerdo se aplica a los documentos redactados solamente en español o en portugués, que son los idiomas oficiales de los Estados del MERCOSUR. Los documentos de países no mercosureños que usan la lengua española o portuguesa, así como los documentos plurilingües que las incluyen (v.gr. los extractos de las partidas de estado civil que extienden varios

\footnotetext{
${ }^{3}$ Esta interpretación es congruente con el artículo 32 de la Convención de Viena sobre el derecho de los tratados, que permite recurrir a los trabajos preparatorios cuando las disposiciones de un tratado, tomadas en su contexto, son equívocas o conducen a resultados no razonables. Aunque Brasil y Bolivia no son partes de la Convención de Viena (a diferencia de Argentina, Chile, Paraguay y Uruguay), sus disposiciones sobre interpretación de los tratados son generalmente consideradas como declaratorias del derecho internacional consuetudinario en vigor. Ver Brownlie, Ian, Principles of Public International Law, 6th ed., Oxford University Press, Oxford y New York, 2003, pág. 602.
} 
países europeos), quedan comprendidos en el Acuerdo. Todos los otros idiomas quedan excluidos, aunque se hayan generalizados por el uso o sean de facilísima comprensión.

\section{La Definición de “Trámite Migratorio” y SU Interpretación Restrictiva por las Autoridades Argentinas}

El segundo aspecto controversial concierne a la interpretación del artículo 1, a saber: qué constituye un "trámite migratorio" en los términos del Acuerdo. Es que, no obstante lo dispuesto en los artículos 1 y 3 del Acuerdo, el Registro Nacional de las Personas argentino (RENAPER), organismo cuya función es identificar y registrar a todas las personas de existencia física que se domicilian en territorio argentino ${ }^{4}$, sigue exigiendo la partida de nacimiento original traducida por traductor público nacional y certificada por el colegio argentino de traductores a fin de otorgar el documento nacional de identidad como residente (DNI de extranjero), a tenor de lo dispuesto en el artículo 64 del decreto-ley 8.204/1963․ No está claro si la decisión del RENAPER se funda en una interpretación textual rígida (y, en todo caso, incorrecta) del artículo 2 del Acuerdo, que exime de traducción a los "testimonios de partidas o certificados de nacimiento" pero no a las "partidas originales"; o que considera que el otorgamiento de DNI no constituye parte integrante del trámite migratorio que provoca la aplicación del Acuerdo.

La primera interpretación, reitero, sería incorrecta, ya que "partidas", "testimonios" y "certificados", si no son siempre indiferenciables, cumplen una función idéntica de acreditación del estado civil del interesado (principio de equivalencia funcional). La única diferenciación válida es entre el registro o asiento del acto (del nacimiento, matrimonio, defunción, etc.) y la copia o constancia otorgada sobre la base de las enunciaciones originarias y las anotaciones posteriores del acto, cualquiera sea la forma o denominación que lleve. ${ }^{6}$

La segunda interpretación (que el DNI no es parte del trámite migratorio) también es defendible con base en el texto, esta vez del artículo 1 del Acuerdo, pero contradice su "objeto y fin" de facilitar los trámites de entrada, salida y estadía para los nacionales de los Estados del MERCOSUR. Obviamente que los documentos presentados a efectos de obtener una visa en cualquiera de las categorías migratorias (familiar de argentino, estudiante, trabajador, inversor, rentista, etc.) ante un consulado, o de extender el plazo de estadía u obtener la autorización para residir ante la Dirección Nacional de

\footnotetext{
${ }^{4}$ Artículos 1 y 2, ley 17.671 de Registro Nacional de las Personas, BO 12/3/1968.

${ }^{5}$ Decreto-ley 8.204/1963 de Régimen del Registro del Estado Civil y Capacidad de las Personas, BO $3 / 10 / 1963$.

${ }^{6}$ Sobre la validez extraterritorial de los actos de estado civil, ver Oyarzábal, Mario, "Los actos de estado civil en el derecho internacional privado y la competencia específica de los agentes diplomáticos y consulares argentinos", Anuario Argentino de Derecho Internacional, vol. XIII, 2004, pág. 125 y sigs. y la bibliografía citada.
} 
Migraciones (DNM), ${ }^{7}$ quedan dispensados de traducción, ya que el artículo 1 los menciona expresamente. Pero si la residencia (temporaria o permanente) en la Argentina recién se consolida con el otorgamiento del DNI por el RENAPER, el trámite correspondiente a su obtención, sea o no intrínsecamente migratorio, constituye un paso ineludible para garantizar el libre tránsito y la permanencia de los extranjeros beneficiarios del Acuerdo en territorio argentino. De ello se sigue que la denegatoria a otorgar el DNI por falta de traducción de la partida de nacimiento al español, frustra los fines del Acuerdo. Por lo demás, ¿cuál es el sentido de eximir de traducción de la partida para el trámite de la visa, si el interesado debe igualmente hacerla traducir para obtener su DNI?

No hay que minimizar, sin embargo, los inconvenientes a que conduce esta interpretación (de eximir de traducción a las partidas con destino al RENAPER). Además de la dificultad de registrar partidas en idioma extranjero, como es previsible que al RENAPER le sea requerido otorgar testimonios en español de las mismas, se multiplica el riesgo de consignar errores en los datos esenciales de la persona y generar discordancias

${ }^{7}$ Las diversas categorías migratorias y las condiciones para la admisión y permanencia de extranjeros en el territorio argentino surgen de la ley 25.871 de Política migratoria nacional, BO 21/1/2004, que aún no ha sido reglamentada. En todo lo que la ley 25.871 no resulta operativa, rige el decreto $1.023 / 94$, BO 5/7/1994, que aprueba el Reglamento de migración. También se aplica la resolución 310/2003 del Ministerio del Interior (MI) de 5/11/2003, que exime a los nacionales de países limítrofes del régimen del decreto $1.117 / 1998, \mathrm{BO} 6 / 10 / 1998$, el cual prohíbe a los extranjeros que ingresaron al territorio nacional con posterioridad al 15 de octubre de 1998 en categoría de residentes transitorios (turistas, negocios, etc.) cambiar de categoría a temporario estudiante o temporario trabajador. Por su parte, la disposición DNM 2.079/2004 de 28/1/2004 suspendió las medidas de entrañamiento de ciudadanos del MERCOSUR, Bolivia y Chile que se encuentran en situación de irregularidad migratoria en la Argentina, con excepción de aquellas expulsiones fundadas en la existencia de antecedentes penales de las personas afectadas. Finalmente, por disposición DNM 53.253/2005 de 13/12/2005 se implementó el Programa nacional de normalización documentaria migratoria para extranjeros nativos de los Estados del Mercado Común del Sur (MERCOSUR) y sus Estados Asociados, que permite a las personas residentes en forma irregular en la Argentina obtener una "residencia precaria" que les autoriza a estudiar, trabajar, entrar, salir y permanecer en el país sin inconvenientes, con la sola acreditación de su nacionalidad y ausencia de antecedentes delictuales, y al cabo de dos años obtener la residencia definitiva. La información oficial sobre el Programa está disponible en http:// www.patriagrande.gov.ar. Todas estas disposiciones de la DNM argentina regirán hasta la entrada en vigor del Acuerdo sobre regularización migratoria interna de ciudadanos del MERCOSUR, Bolivia y Chile, firmado en Brasilia el 5/12/2002, MERCOSUR/CMC/DEC N N $^{\circ}$ /02, cuyo artículo 1 permite a los nacionales de un Estado Parte que se encuentren en el territorio de otro Estado Parte, efectuar la tramitación migratoria de su residencia en este último sin necesidad de egresar del mismo. Este Acuerdo no ha sido ratificado aún por la Argentina. Hasta la fecha sólo ha sido aprobado por Brasil por decreto legislativo 923 de 2005, DOU 16/9/2005, y por Chile según comunicación al depositario del Acuerdo de 18/11/2005. Para la entrada en vigor se requiere la ratificación por todos los Estados Partes (art. 5 del Acuerdo). E1 5/8/2004, por circular 31 del Ministerio del Interior-Gabinete del Ministro, el Gobierno de Chile adoptó medidas migratorias con relación a los ciudadanos argentinos de igual naturaleza que las establecidas por la resolución MI 310/2003 y la disposición DNM 2.079/2004 argentinas citadas. Ver, en general, Novick, Susana, "La reciente política migratoria argentina en el contexto del MERCOSUR", en Novick, Susana, Hener, Alejandro y Dalle, Pablo, El Proceso de integración MERCOSUR: de las Políticas Migratorias y de Seguridad a las Trayectorias de los Inmigrantes, IIGG Documentos de Trabajo, No 46, Instituto de Investigaciones Gino Germani, Facultad de Ciencias Sociales, Universidad de Buenos Aires, 2005, págs. 1-63, disponible en http://www.iigg.fsoc. uba.ar/Publicaciones/DT/dt46.pdf 
con el original conservado en el extranjero. No obstante ello, creo que la dispensa de traducción de la partida de nacimiento presentada para obtener el DNI surge implícitamente del Acuerdo, que no puede ser ignorado, en consideración de la preeminencia que tienen los tratados internacionales sobre las leyes internas en el ordenamiento jurídico argentino (art. 75 inc. 22, Constitución Nacional).

\section{ANEXo}

Acuerdo sobre Exención de Traducción de Documentos Administrativos para Efectos de Inmigración entre los Estados Partes del MERCOSUR, la República de Bolivia y la República de Chile

La República Argentina, la República Federativa del Brasil, la República del Paraguay y la República Oriental del Uruguay, Estados Partes del MERCOSUR, la República de Bolivia y la República de Chile, Estados Asociados, todas denominadas en lo sucesivo "Estados Partes", a efectos del presente Acuerdo,

Visto el Tratado de Asunción, el Protocolo de Ouro Preto, el Acuerdo de Complementación Económica N ${ }^{0}$ 35, el Acuerdo de Complementación Económica N 36 y las Decisiones del Consejo del Mercado Común N 14/96 "Participación de Terceros Países Asociados en Reuniones del MERCOSUR" y N 12/97 "Participación de Chile en Reuniones del MERCOSUR";

CONSIDERANDO que los instrumentos fundacionales del MERCOSUR establecen el compromiso, por parte de los Estados Partes, de armonizar sus legislaciones;

Reafirmando el deseo de los Estados Partes del MERCOSUR y Asociados de fortalecer los fraternales vínculos existentes entre ellos y de aumentar la fluidez de la circulación de los beneficiarios del presente Acuerdo;

ENFATIZANDO la importancia de promover, en instrumentos jurídicos de cooperación, el libre tránsito y la permanencia de los ciudadanos de los Estados Partes del presente Acuerdo, mediante la facilitación del trámite migratorio;

Teniendo en CUenta la voluntad de los Estados democráticos de avanzar en mecanismos tendientes a la eliminación gradual de los trámites de entrada, salida y estadía en los Estados Partes;

EN CONCORDANCIA con la Decisión CMC N $7 / 96$, que motivó la necesidad de avanzar en la elaboración de mecanismos comunes para profundizar la cooperación en las áreas de competencia de los Ministerios del Interior o equivalentes,

\section{Acuerdan:}

\section{Artículo 1}

El presente Acuerdo se aplicará a los documentos presentados a efectos de trámites migratorios referentes a solicitud de visa, renovación de plazo de estadía y concesión de permanencia. 
Artículo 2

Los nacionales de cualquiera de los Estados Partes quedan dispensados, en los trámites administrativos migratorios señalados en el Artículo 1, de la exigencia de traducción de los siguientes documentos:

i) Pasaporte 2) Cédula de Identidad 3) Testimonios de Partidas o Certificados de Nacimiento y de Matrimonio 4) Certificado de Ausencia de Antecedentes Penales.

\section{Artículo 3}

La exención de traducción de documentos establecida por el presente Acuerdo no dispensa a sus beneficiarios de las leyes y reglamentos en materia migratoria, vigentes en cada uno de los Estados Partes.

\section{Artículo 4}

Existiendo dudas fundadas en cuanto al contenido del documento presentado, el país de ingreso podrá, excepcionalmente, exigir la traducción del respectivo documento.

\section{Artículo 5}

1. El presente Acuerdo entrará en vigor treinta (30) días después del depósito del instrumento de ratificación de, por lo menos, un Estado Parte del MERCOSUR y de por lo menos un Estado Asociado.

Para los demás Estados Partes, entrará en vigor el trigésimo día posterior al del depósito del respectivo instrumento de ratificación.

2. El presente Acuerdo no restringirá los otros que sobre la materia pudieran existir entre los Estados Partes, en la medida que no se opongan al mismo.

3. La República del Paraguay será depositaria del presente Acuerdo, de los instrumentos de ratificación y enviará copia debidamente autenticada de los mismos a los demás Estados Partes.

4. La República del Paraguay notificará a los demás Estados Partes la fecha de entrada en vigor del presente Acuerdo y la fecha del depósito de los instrumentos de ratificación o de la notificación.

5. Cualquier Estado Parte podrá denunciar el presente Acuerdo mediante notificación escrita a los demás Estados Partes. La denuncia surtirá efecto 6 (seis) meses después de la fecha de notificación.

\section{Firmantes}

Hecho en Florianópolis, República Federativa del Brasil, a los 15 días del mes de Diciembre de 2000, en un ejemplar original, en los idiomas español y portugués, siendo ambos textos igualmente auténticos. 
Por el Gobierno de la República Argentina

Adalberto Rodríguez Giavarini

Por el Gobierno de la República de Bolivia

Javier Murillo

Por el Gobierno de la República Federativa de Brasil

Luis Felipe Lampreia

Por el Gobierno de la República de Chile

María Soledad Alvear Valenzuela

Por el Gobierno de la República del Paraguay

Juan Esteban Aguirre

Por el Gobierno de la República Oriental del Uruguay

Didier Opertti

\section{BIBLIOGRAFÍA}

Brownlie, Ian, Principles of Public International Law, 6th ed., Oxford University Press, Oxford y New York, 2003.

Marmora, Lelio, "Políticas migratorias consensuadas en América Latina", en Estudios Migratorios Internacionales, año 17, $\mathrm{N}^{\circ}$ 50, Buenos Aires, 2003.

Novick, SUSANA, "La reciente política migratoria argentina en el contexto del MERCOSUR", en Novick, Susana, Hener, Alejandro y DALle, Pablo, El Proceso de integración MERCOSUR: de las Políticas Migratorias y de Seguridad a las Trayectorias de los Inmigrantes, IIGG Documentos de Trabajo, $N^{\circ}$ 46, Instituto de Investigaciones Gino Germani, Facultad de Ciencias Sociales, Universidad de Buenos Aires, 2005, págs. 1-63, disponible en http://www.iigg.fsoc.uba. ar/Publicaciones/DT/dt46.pdf

Oyarzábal, Mario, "Los actos de estado civil en el derecho internacional privado y la competencia específica de los agentes diplomáticos y consulares argentinos", en Anuario Argentino de Derecho Internacional, vol. XIII, Asociación Argentina de Derecho Internacional, Córdoba, 2004, págs. 125-140.

SASSONE, Susana MARía, "Las condiciones de la movilidad para los ciudadanos en el MERCOSUR: hacia la reconfiguración de las territorialidades transfronterizas", en Territoires et sociétés $d u$ MERCOSUR: jeux et unjeux de l'intégration, L'ordinaire Latino-américain, No 196, Institut Pluridisciplinaire pour les Etudes sur l'Amérique Latine á Toulouse, 2004, págs. 50-62. 